\title{
The Role of Second Phases on the Creep Behavior of As-Cast and Hot-Extruded Mg-Ca-Zr Alloys
}

\author{
S. YOU ${ }^{1,3}$ Y. HUANG,${ }^{1}$ H. DIERINGA ${ }^{1}$ E. MAAWAD, ${ }^{2}$ \\ W. GAN ${ }^{2}$ K.U. KAINER, ${ }^{1}$ and N. HORT ${ }^{1}$ \\ 1.-Institute of Materials Research, Helmholtz-Zentrum Geesthacht, Max-Planck-Straße 1, 21502 \\ Geesthacht, Germany. 2.-German Engineering Materials Centre (GEMS), Helmholtz-Zentrum \\ Geesthacht, Max-Planck-Straße 1, 21502 Geesthacht, Germany. 3.—e-mail: sihang.you@hzg.de
}

\begin{abstract}
The effect of second phases on the creep behavior of $\mathrm{Mg}-\mathrm{Ca}-\mathrm{Zr}$ alloys was investigated. Casting and hot-extrusion processes were performed to prepare $\mathrm{Mg}-x \mathrm{Ca}-0.5 \mathrm{Zr}$ ( $x=0$ wt.\%, $0.3 \mathrm{wt} . \%$ and $0.6 \mathrm{wt} . \%$ ) alloys with different morphologies and distributions of second phases. The as-cast microstructures of $\mathrm{Mg}-\mathrm{Ca}-\mathrm{Zr}$ alloys consisted of an $\mathrm{Mg}$ matrix and coarse $\mathrm{Mg}_{2} \mathrm{Ca}$ intermetallic compounds distributed at the grain boundaries. The hot-extruded microstructures exhibited finer $\mathrm{Mg}_{2} \mathrm{Ca}$ spherical particles and precipitates distributed homogeneously inside the matrix and along the grain boundaries. The results of creep tests suggested that the viscous glide of dislocation and dislocation climb were the dominant creep mechanisms of $\mathrm{Mg}-\mathrm{Ca}-\mathrm{Zr}$ alloys crept at $200^{\circ} \mathrm{C}$. The creep property was strongly related to the morphology and distribution of the $\mathrm{Mg}_{2}$ Ca phases. The finer and more homogeneously distributed particles showed a better strengthening effect than the coarser intermetallic compounds distributed along the grain boundaries.
\end{abstract}

\section{INTRODUCTION}

Magnesium is the lightest structural metal with a high specific strength and good electric conductivity as well as thermal conductivity. ${ }^{1,2}$ However, owing to their low strength and formability at room temperature and poor creep resistance at elevated temperatures, the present applications of magnesium alloys are still limited. In recent years, great efforts have been made to develop high-creep-resistant $\mathrm{Mg}$ alloys. The addition of rare earth $(\mathrm{RE})$ elements is generally regarded as the most effective way to improve the creep resistance of $\mathrm{Mg}$ alloys. ${ }^{3}$ However, RE elements are still too expensive to be widely used for this purpose. ${ }^{4}$ Among all non-RE alloying elements, $\mathrm{Ca}$ is expected to be an effective alloying element in the development of creep-resistant $\mathrm{Mg}$ alloys due to its low cost and even lower density than $\mathrm{Mg}$. It has been reported that the creep resistance of most widely used $\mathrm{Mg}-\mathrm{Al}$ based alloys can be enhanced by $\mathrm{Ca}$ addition, ${ }^{5,6}$ since $\mathrm{Ca}$ can consume $\mathrm{Al}$ solutes and introduce more thermally stable phases or precipitates. ${ }^{7}$ Moreover, the mechanical properties and creep resistance of a ternary Mg-Zn-Sn alloy was reported to be significantly improved by the addition $1.0 \mathrm{wt} . \%$ of $\mathrm{Ca}{ }^{8}$ The addition of $\mathrm{Ca}$ also results in refined grains, ${ }^{9}$ an enhanced ignition point ${ }^{10}$ and a weakened texture which leads to the improvement of ductility for $\mathrm{Mg}$ alloys. ${ }^{11}$

In $\mathrm{Mg}$-Ca-based alloys, $\mathrm{Mg}_{2} \mathrm{Ca}$ phases play an important role in enhancing the creep properties, as it is a thermally stable compound with a high melting point ${ }^{12}$ and can effectively hinder grain boundary sliding and dislocation motion even at elevated temperatures. ${ }^{13}$ Despite reports in the literature regarding the creep behavior of many $\mathrm{Ca}$-containing $\mathrm{Mg}$ alloy systems in recent years, the role of the distribution and morphology of second phases on the creep behavior of binary $\mathrm{Mg}$-Ca alloys has rarely been investigated. The present work aims to investigate the creep behavior of $\mathrm{Mg}-\mathrm{Ca}$ alloys with different $\mathrm{Ca}$ contents and to clarify the relationship between the creep resistance and the distribution and morphology of second phases for the alloys. Casting and hot-extrusion processes have been used to prepare alloys with different distributions of second phases. A small amount of $\mathrm{Zr}$ was 
added as the grain refiner for the alloys. As-cast and hot-extruded $\mathrm{Mg}-0.5 \mathrm{Zr}$ alloys were prepared to be used as benchmarks.

\section{EXPERIMENTAL PROCEDURES}

Three alloys with different $\mathrm{Ca}$ concentrations (wt.\%), Mg-0.5Zr, Mg-0.3Ca-0.5Zr and $\mathrm{Mg}-0.6 \mathrm{Ca}-$ $0.5 \mathrm{Zr}$ alloys, were prepared by permanent mold direct chill casting. ${ }^{14}$ Pure $\mathrm{Mg}$ was melted in a mild steel crucible under a protective atmosphere $\mathrm{Ar}+$ 2 vol.\% SF6). Pure Ca and Mg-33.3 wt.\% Zr master alloy were then added into the melt at $750^{\circ} \mathrm{C}$. The melt was then homogenized by mechanical stirring under $200 \mathrm{rpm}$ for $20 \mathrm{~min}$. After that, the melt was poured into a steel crucible preheated to $680^{\circ} \mathrm{C}$ and held at $680^{\circ} \mathrm{C}$ for $20 \mathrm{~min}$ with gas protection. Finally, the melt was solidified by lowering the crucible into cooling water with a rate of $10 \mathrm{~mm} / \mathrm{s}$. The ingots for hot extrusion were first solid-solution heat-treated (T4) at $500^{\circ} \mathrm{C}$ for $8 \mathrm{~h}$ followed by water quenching. These T4-treated ingots were then machined to a cylinder with a size $\Phi 49 \times 150 \mathrm{~mm}$ and preheated at $400^{\circ} \mathrm{C}$ for $1 \mathrm{~h}$. The indirect extrusion process was carried out at $400^{\circ} \mathrm{C}$ with a ram speed of $2 \mathrm{~mm} / \mathrm{s}$ and an extrusion ratio of 25:1 to produce round profiles with a diameter of $10 \mathrm{~mm}$.

The specimens for optical microscope (OM) observations were ground with silicon carbide abrasive paper, polished with water-free colloidal silica and then etched with acetic-picric solution. OM observations were performed with a Leica DMI5000 microscope with an attached digital camera. The average grain size was measured by the linear intercept method from the micrographs. Microstructures were investigated using a TESCAN Vega SB-U III scanning electron microscope (SEM) under an accelerating voltage of $15 \mathrm{kV}$ and working distance of $15 \mathrm{~mm}$ in backscatter electron (BSE) mode. The volume fraction of the intermetallic phases was determined by SEM BSE image analysis using ImageJ software. The threshold and contrast were adjusted to obtain a high contrast between the intermetallic phase regions and the matrix. At least 10 micrographs were used to determine the amount of these phases. Specimens for transmission electron microscope (TEM) were first ground mechanically to a thickness of about $120 \mu \mathrm{m}$ and then thinned by electropolishing in a twin jet electropolisher using a polishing solution of $2.5 \% \mathrm{HClO}_{4}$ and $97.5 \%$ ethanol at $-45^{\circ} \mathrm{C}$ and a voltage of $40 \mathrm{~V}$. The TEM examinations were carried out on a Philips CM200 instrument operating at $200 \mathrm{kV}$. The bright-field mode was used for imaging the microstructure. The diffraction patterns of intermetallic particles were obtained through selected area electron diffraction (SAED). The synchrotron radiation diffraction was also used for the phase analysis, which was carried out at the highenergy x-ray beamline HEMS P07B of PETRA III, DESY (Deutsches Elektronen-Synchrotron). A monochromatic beam was used with a wavelength of $0.014235 \mathrm{~nm}$ and a beam cross-section of $0.7 \times 0.7 \mathrm{~mm}^{2}$. The acquisition time of each diffraction pattern was set to $0.5 \mathrm{~s}$. The diffraction patterns (Debye-Scherrer rings) were recorded by a detector with an effective pixel size of $200 \mu \mathrm{m}$, placed $1950 \mathrm{~mm}$ behind the sample, calibrated by a $\mathrm{LaB}_{6}$ standard powder sample. The diffraction patterns were integrated and analyzed with the software Fit2D. Cylindrical specimens of $15 \mathrm{~mm}$ in length and $6 \mathrm{~mm}$ in diameter were used for the compression creep tests. The constant stress compression creep tests were performed on both the as-cast and hotextruded $\mathrm{Mg}-x \mathrm{Ca}-0.5 \mathrm{Zr}$ alloys at $200^{\circ} \mathrm{C}$ under a range of stresses using Applied Test System creep machines.

\section{RESULTS}

The as-cast and hot-extruded optical microstructures of the investigated alloys are shown in Fig. 1. Due to the addition of $\mathrm{Zr}$, a relatively homogeneous microstructure was formed during the direct chill casting, even though the cooling process was rapid with water quenching. The grain sizes of as-cast alloys were measured as $221 \pm 101 \mu \mathrm{m}$ for $\mathrm{Mg}$ $0.5 \mathrm{Zr}, \quad 79 \pm 39 \mu \mathrm{m}$ for $\mathrm{Mg}-0.3 \mathrm{Ca}-0.5 \mathrm{Zr}$ and $69 \pm 36 \mu \mathrm{m}$ for Mg-0.6Ca-0.5Zr alloy, respectively. The grain sizes of hot-extruded alloys containing 0 wt.\%, 0.3 wt.\% and 0.6 wt.\% Ca were measured to be $33.7 \pm 15.3 \mu \mathrm{m}, 15.5 \pm 7.1 \mu \mathrm{m}$ and $8.3 \pm 3.5 \mu \mathrm{m}$, respectively. The grains of both the as-cast and extruded alloys are significantly refined with increasing $\mathrm{Ca}$ content.

Figure 2 presents the SEM (BSE) microstructures of the as-cast and hot-extruded alloys. The as-cast microstructures of Ca-containing alloys are mainly composed of the $\alpha-\mathrm{Mg}$ matrix and intermetallic phases distributed at the grain boundaries. The volume fraction of these intermetallic compounds increases remarkably with increasing Ca content. It is $0.81 \pm 0.11 \%$ for as-cast $\mathrm{Mg}-0.3 \mathrm{Ca}-0.5 \mathrm{Zr}$ and $2.05 \pm 0.30 \%$ for $\mathrm{Mg}-0.6 \mathrm{Ca}-0.5 \mathrm{Zr}$. The morphology of these compounds in the as-cast $\mathrm{Mg}-0.6 \mathrm{Ca}-0.5 \mathrm{Zr}$ alloy is more continuous than that in the alloy with 0.3 wt.\% Ca. For the hot-extruded alloys, the amount of intermetallic particles increases noticeably with increasing addition of $\mathrm{Ca}$. The volume fractions of intermetallic particles in hot-extruded $\mathrm{Mg}-0.3 \mathrm{Ca}-0.5 \mathrm{Zr}$ and $\mathrm{Mg}-0.6 \mathrm{Ca}-0.5 \mathrm{Zr}$ are $0.41 \pm 0.08 \%$ and $1.47 \pm 0.15 \%$, respectively. However, the morphology and distribution of these particles are significantly different from those in the as-cast alloys. It can be observed the bright particles distribute homogeneously inside the grains and along the grain boundaries.

The synchrotron diffraction line profiles of as-cast and hot-extruded alloys are shown in Fig. 3a and b, respectively. Only the peaks of $\alpha-\mathrm{Mg}$ are found in the line profile of the as-cast and hot-extruded $\mathrm{Mg}$ $0.5 \mathrm{Zr}$ alloy. With $0.3 \mathrm{wt} . \% \mathrm{Ca}$ addition, some additional peaks of the $\mathrm{Mg}_{2} \mathrm{Ca}$ phase with relatively low 

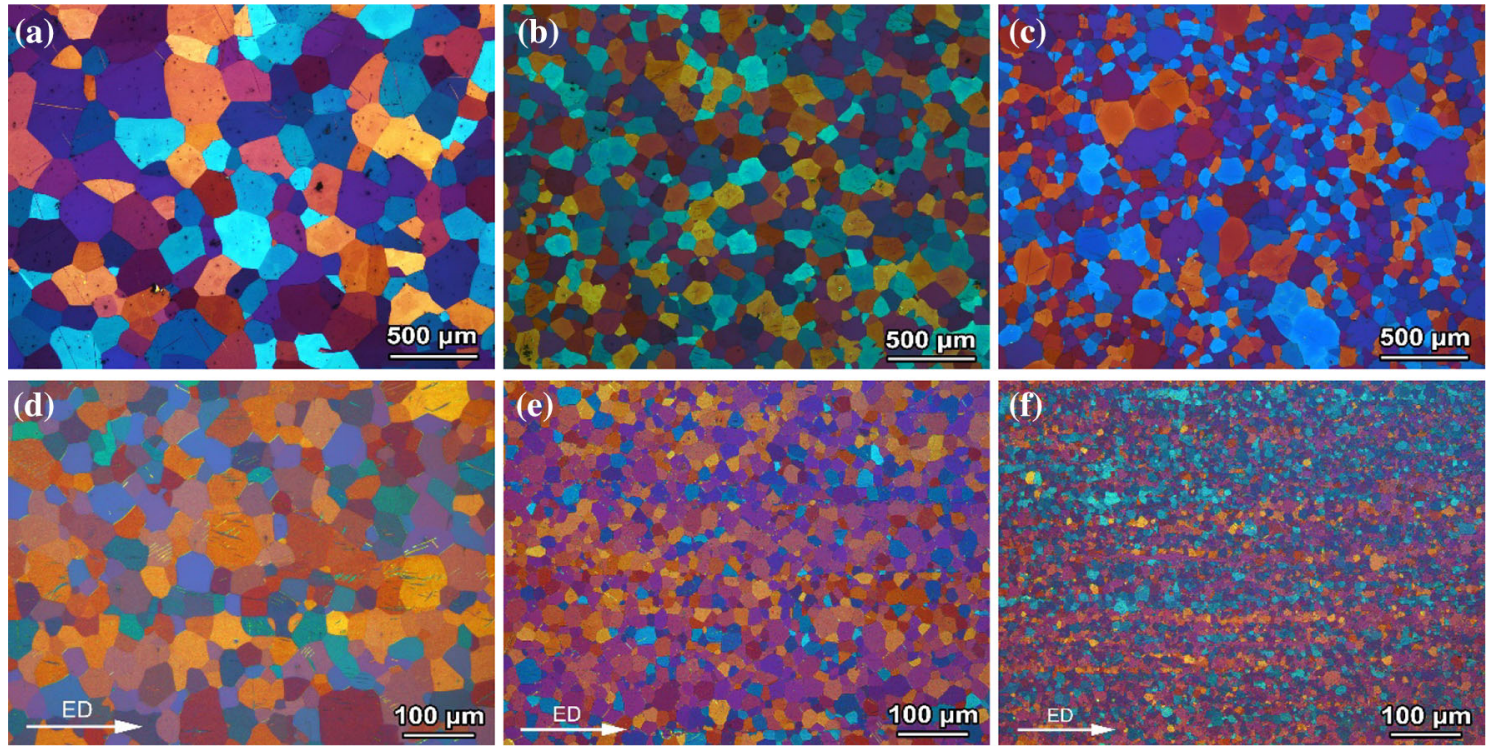

Fig. 1. Optical micrographs of as-cast (a) Mg-0.5Zr, (b) Mg-0.3Ca-0.5Zr, (c) Mg-0.6Ca-0.5Zr alloys and hot-extruded (d) Mg-0.5Zr, (e) Mg$0.3 \mathrm{Ca}-0.5 \mathrm{Zr}$, (f) $\mathrm{Mg}-0.6 \mathrm{Ca}-0.5 \mathrm{Zr}$ alloys parallel to extrusion direction $(E D)$.
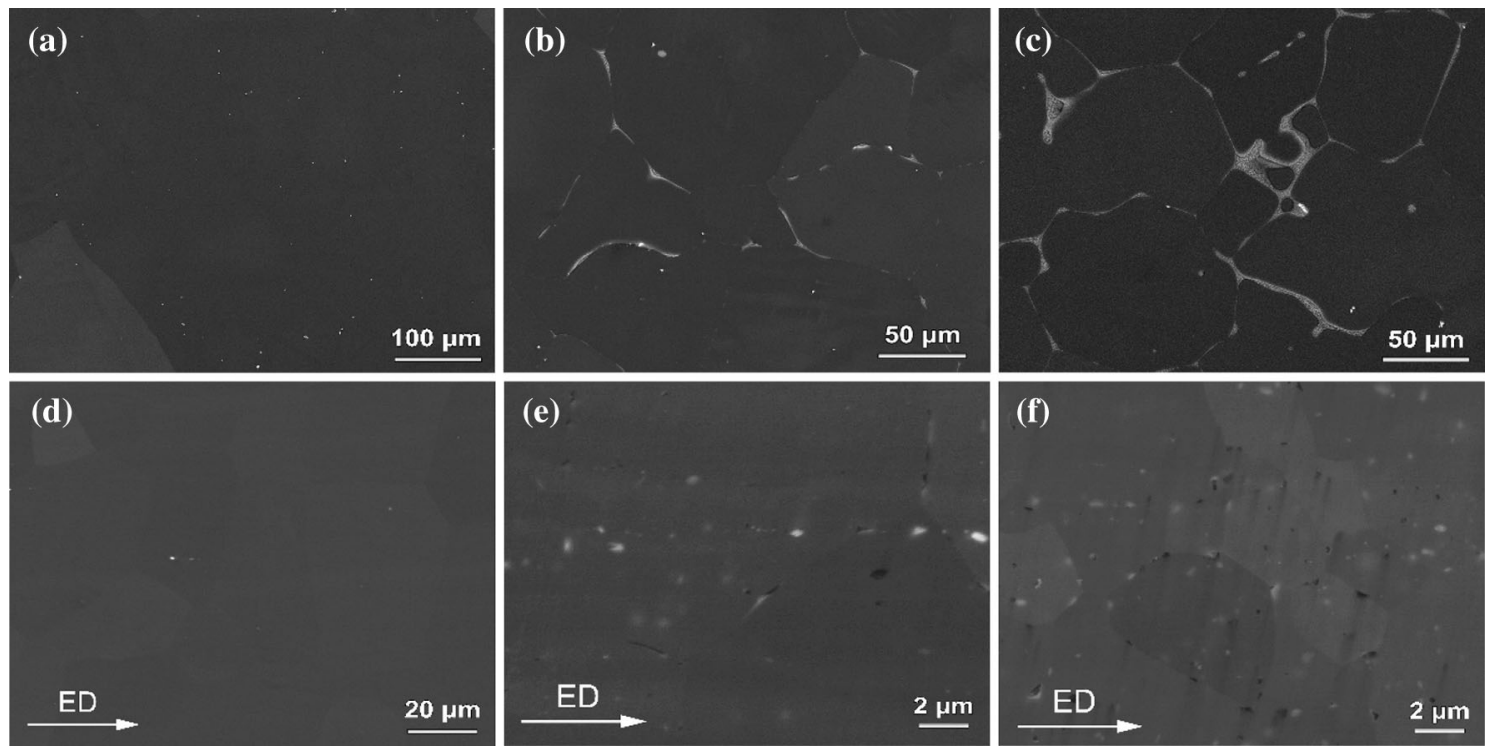

Fig. 2. SEM micrographs of as-cast (a) Mg-0.5Zr, (b) Mg-0.3Ca-0.5Zr, (c) Mg-0.6Ca-0.5Zr and hot-extruded (d) Mg-0.5Zr, (e) Mg-0.3Ca-0.5Zr, (f) Mg-0.6Ca-0.5Zr alloys.

intensity appear besides the $\mathrm{Mg}$ peaks. The intensity of the $\mathrm{Mg}_{2} \mathrm{Ca}$ peaks increases significantly with increasing Ca content to $0.6 \mathrm{wt} . \%$ in both the as-cast and hot-extruded alloys. This indicates that both of the intermetallic compounds in the as-cast microstructures and the spherical intermetallic particles in the hot-extruded microstructures are $\mathrm{Mg}_{2} \mathrm{Ca}$ phases. The amount of these intermetallic phases increase with increasing Ca content, which is consistent with the SEM results shown in Fig. 2.

In the hot-extruded Mg-Ca-Zr alloys, apart from those spherical particles found by SEM observations, a few fine precipitates in the matrix of nanometer order were also detected by TEM observations (Fig. 4). These small precipitates have a disc shape in the [12 10$]$ direction, showing that they lie on the basal plane of the $\alpha-\mathrm{Mg}$ matrix. The EDS analysis of precipitates 1 and 2 indicate that they are Ca-enriched. In this work, due to the low content of $\mathrm{Ca}$ and the low number density of these precipitates, it is hard to obtain their diffraction patterns by SAED. In Mg-Ca binary alloys, the $\mathrm{Mg}_{2} \mathrm{Ca}$ phase has been recognized as the only second phase in the Mg-rich region. This second phase was confirmed in the present as-cast material. According to the observations from 

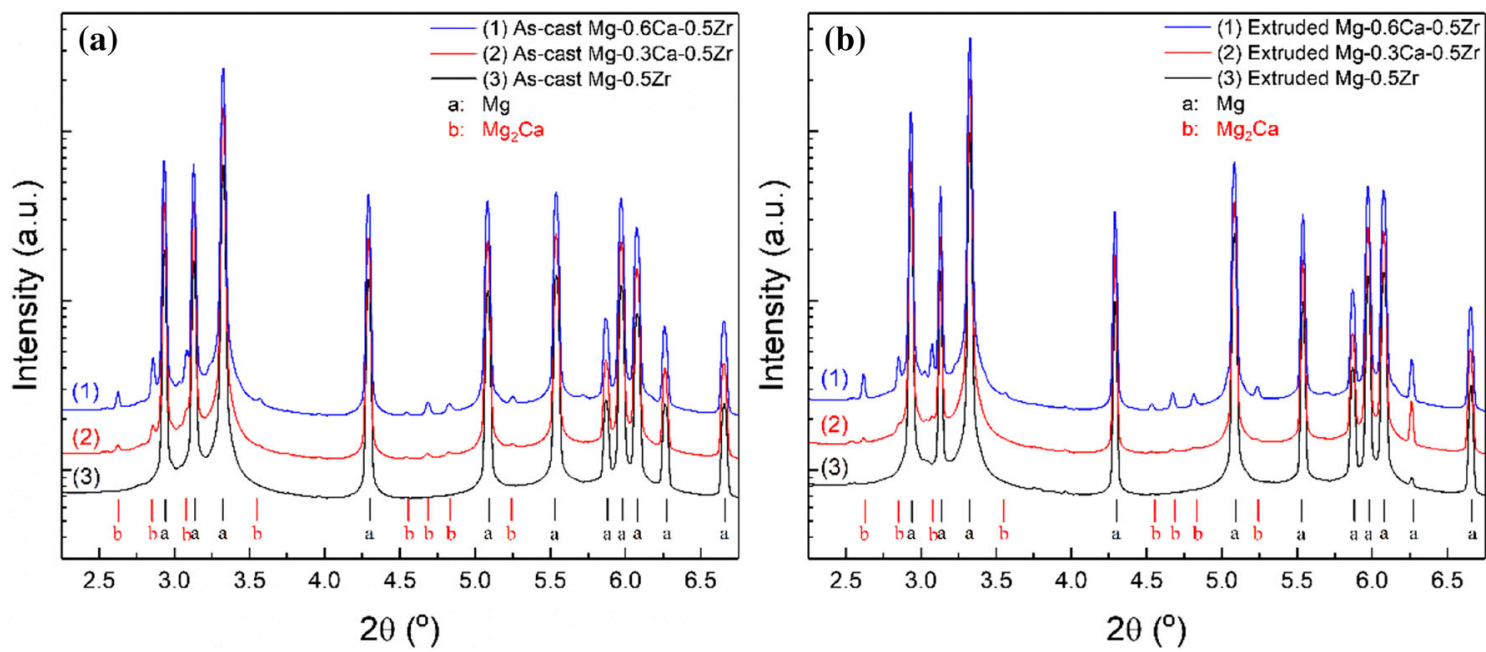

Fig. 3. Synchrotron diffraction line profiles of (a) as-cast and (b) hot-extruded Mg-Ca-Zr alloys.
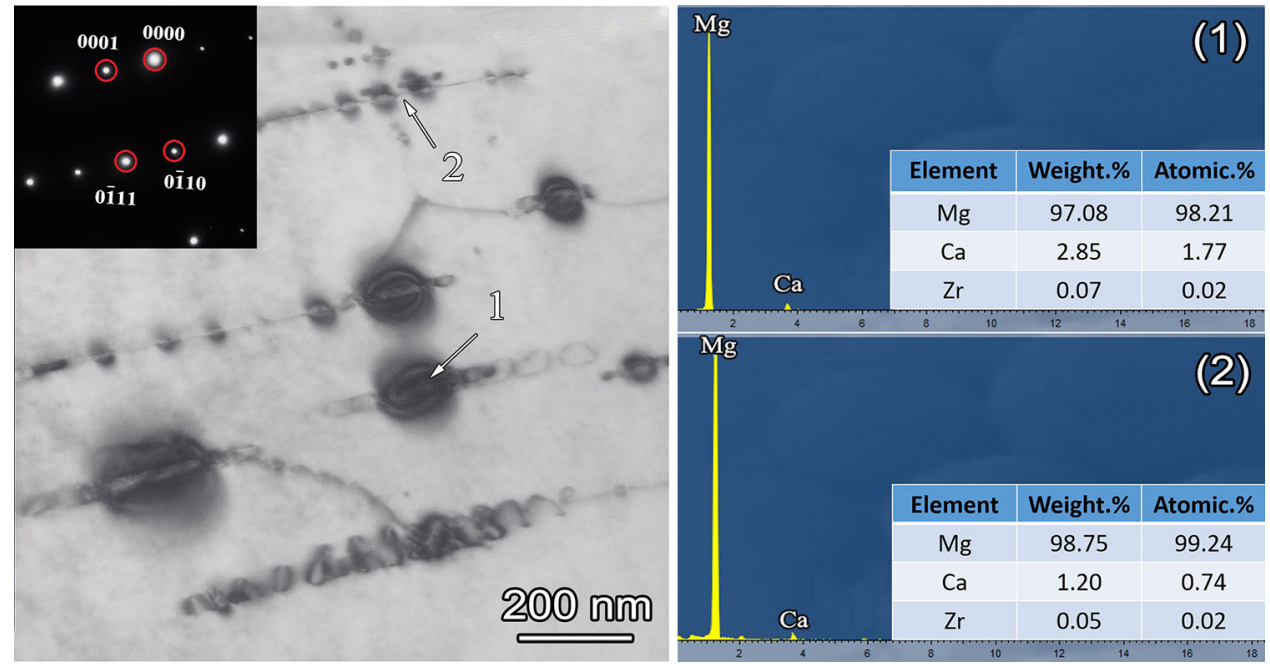

Fig. 4. Bright-field TEM images of extruded Mg-0.3Ca-0.5Zr alloy taken from [1210] and the corresponding SAED pattern. The EDS analysis of positions 1 and 2 are presented in the righthand images (1) and (2).

references ${ }^{15-17}$ these small disc precipitates could be considered as $\mathrm{Mg}_{2} \mathrm{Ca}$ precipitates. Further investigations will be needed to identify them in the future using HAADF techniques.

Figure $5 \mathrm{a}$ and $\mathrm{b}$ present the creep strain curves of the as-cast and hot-extruded alloys, respectively, at $200^{\circ} \mathrm{C}$ and $40 \mathrm{MPa}$. It is found that increasing the Ca content from 0 wt.\% to 0.6 wt.\% improves both the primary and steady-state creep properties of the as-cast alloys. However, a different situation is observed for the hot-extruded $\mathrm{Mg}-\mathrm{Ca}-\mathrm{Zr}$ alloys. The creep property is first significantly enhanced by 0.3 wt.\% Ca addition, but then worsened by further $\mathrm{Ca}$ addition to 0.6 wt.\%.

The double logarithmic plots of the minimum creep rate versus stress with stress exponent $n$ values for the as-cast and hot-extruded $\mathrm{Mg}-\mathrm{Ca}-\mathrm{Zr}$ alloys are presented in Fig. 6a and b, respectively. In order to compare the creep behaviors of alloys with different $\mathrm{Ca}$ contents, all the samples were tested with the same parameters. It can be seen that the minimum creep rates of the as-cast $\mathrm{Mg}-0.5 \mathrm{Zr}$ alloy at all stress levels reduce by around 1 order of magnitude with 0.3 wt.\% Ca addition. With further addition of $\mathrm{Ca}$, the minimum creep rate only decreases slightly. In contrast, for the extruded alloys, the minimum creep rate of extruded $\mathrm{Mg}$ $0.3 \mathrm{Ca}-0.5 \mathrm{Zr}$ alloy is approximately 2 orders of magnitude lower than that of extruded $\mathrm{Mg}-0.5 \mathrm{Zr}$ alloy. With further $\mathrm{Ca}$ addition, the minimum creep rate of extruded alloy continues to increase by 1 order of magnitude.

Under steady-state creep condition, the steadystate creep rate, $\dot{\varepsilon}_{\mathrm{S}}$, can be described as a function of stress, $\sigma$, and temperature, $T$, at elevated temperatures: ${ }^{18}$

$$
\dot{\varepsilon}_{\mathrm{S}}=A \sigma^{n} \exp (-Q / R T)
$$


The Role of Second Phases on the Creep Behavior of As-Cast and Hot-Extruded Mg-Ca-Zr Alloys

(a)

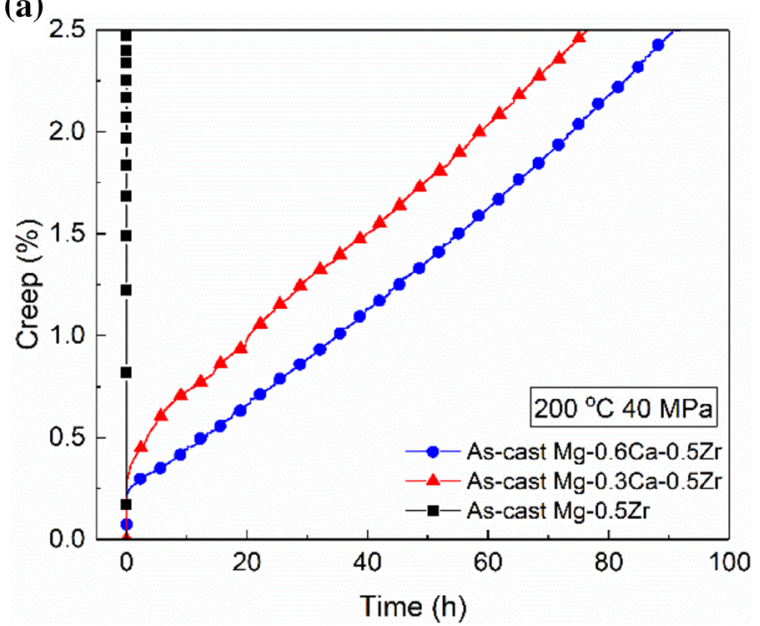

(b)

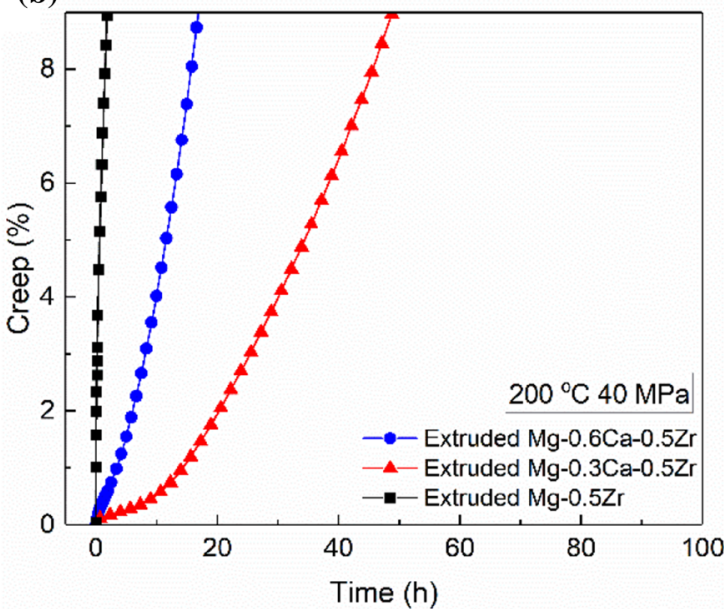

Fig. 5. Creep strain curves for (a) as-cast and (b) hot-extruded Mg-Ca-Zr alloys tested at $200^{\circ} \mathrm{C}$ and $40 \mathrm{MPa}$.

(a)

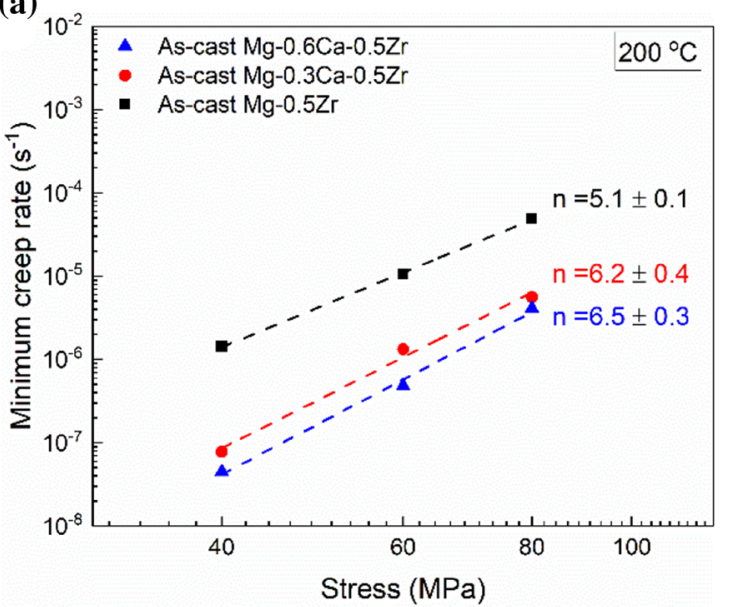

(c)

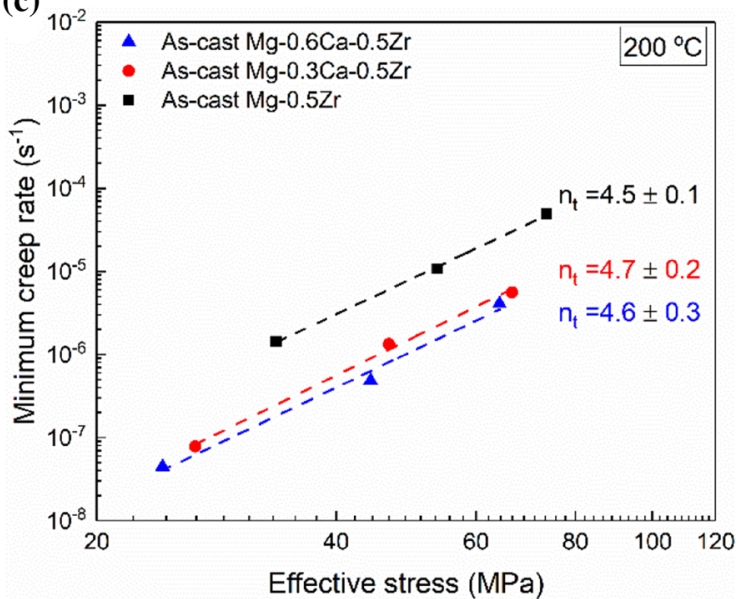

(b)

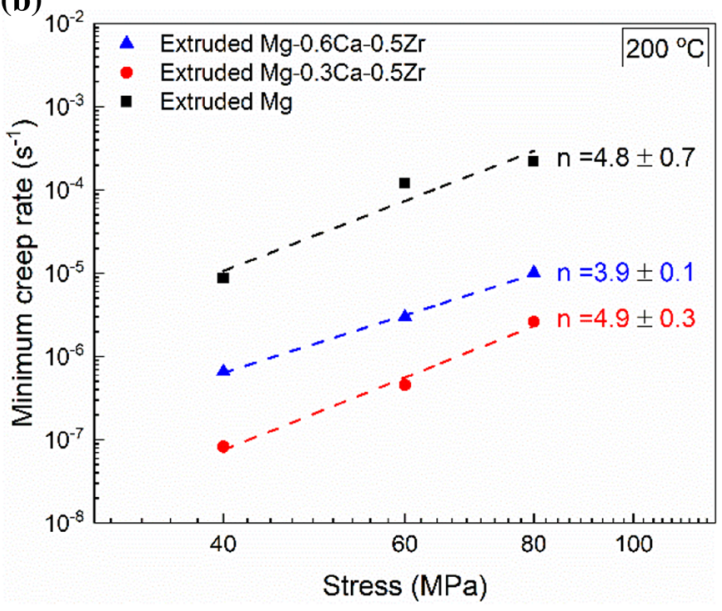

(d)

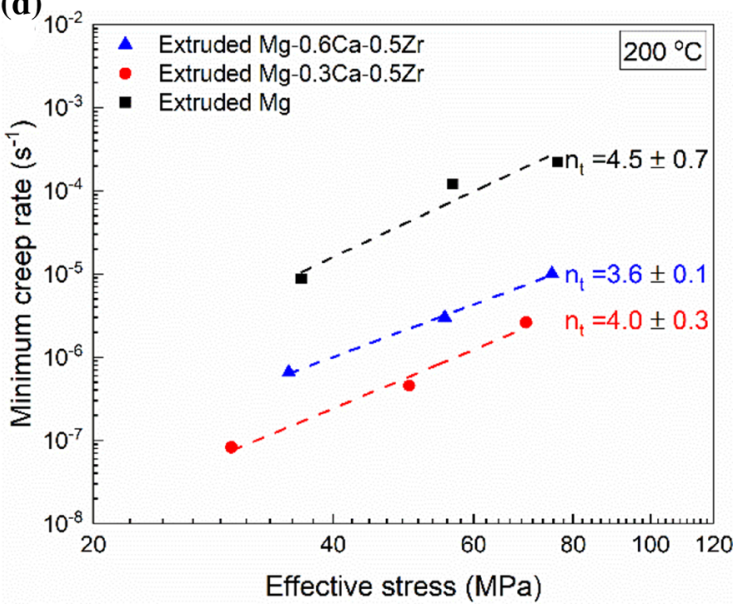

Fig. 6. Comparison of the minimum creep rates between (a) as-cast and (b) hot-extruded alloys at $200^{\circ} \mathrm{C}$, and the minimum creep rate versus effective stress with true stress exponents $\left(n_{\mathrm{t}}\right)$ for $(\mathrm{c})$ as-cast and (d) hot-extruded alloys at $200^{\circ} \mathrm{C}$.

where $A$ is a dimensionless material constant, $n$ is the stress exponent, $Q$ is the activation energy for creep and $R$ is the gas constant. At a given temperature, most of the creep deformations of polycrystalline alloys follow a power-law relationship: 


$$
\dot{\varepsilon}_{\mathrm{s}}=k \sigma^{n}
$$

where $k$ is a constant. The stress exponent $n$ can be evaluated by calculating the slope of the log $\dot{\varepsilon}$ versus $\log \sigma$ plots at a given temperature. This $n$ value is commonly used to infer the dominant creep mechanism for $\mathrm{Mg}$ alloys in specific ranges of stresses at a constant temperature. ${ }^{19}$ Nevertheless, for hightemperature creep deformation of alloys with second-phase particles or precipitates, it is necessary to consider the presence of threshold stress, $\sigma_{t},{ }^{20}$ which is defined as the limiting stress below which no measureable creep rate can be achieved and is related to the interactions between dislocations and precipitates or particles. ${ }^{21}$ When considering the threshold stress, the steady-state creep rate, $\dot{\varepsilon}_{\mathrm{s}}$, can be expressed by the form:

$$
\dot{\varepsilon}_{\mathrm{s}}=k\left(\sigma-\sigma_{t}\right)^{n_{t}}
$$

In this case, the true stress exponent, $n_{\mathrm{t}}$, can be calculated by linear fitting the double logarithm of minimum creep rate, $\dot{\varepsilon}_{\mathrm{s}}$ and the effective stress, $\sigma-\sigma_{t}$. The threshold stresses of as-cast $\mathrm{Mg}-0.5 \mathrm{Zr}$, $\mathrm{Mg}-0.3 \mathrm{Ca}-0.5 \mathrm{Zr}$ and $\mathrm{Mg}-0.6 \mathrm{Ca}-0.5 \mathrm{Zr}$ were calculated to be $7 \mathrm{MPa}, 14 \mathrm{MPa}$ and $16 \mathrm{MPa}$. For the extruded alloys containing $0 \mathrm{wt} . \%, 0.3 \mathrm{wt} . \%$ and 0.6 wt. $\% \mathrm{Ca}$, the threshold stresses were determined to be $4 \mathrm{MPa}, 10 \mathrm{MPa}$ and $5 \mathrm{MPa}$. By plotting the double logarithmic plots of the minimum creep rates versus effective stresses as shown in Fig. 6c and $\mathrm{d}$, the true stress exponent $n_{\mathrm{t}}$ values at $200^{\circ} \mathrm{C}$ for the as-cast and hot-extruded $\mathrm{Mg}-0.5 \mathrm{Zr}, \mathrm{Mg}-$ $0.3 \mathrm{Ca}-0.5 \mathrm{Zr}$ and $\mathrm{Mg}-0.6 \mathrm{Ca}-0.5 \mathrm{Zr}$ alloys are determined to be in the range of 3-5.

\section{DISCUSSION}

In this work, $\mathrm{Zr}$ was added into the alloys as a grain refiner. Its powerful grain refinement effect is due to its good crystallographic matching with $\mathrm{Mg}$ and its high growth restriction. ${ }^{22}$ Since the content of present $\mathrm{Zr}$ addition was relatively low, most of $\mathrm{Zr}$ were dissolved into $\mathrm{Mg}$ matrix. These dissolved $\mathrm{Zr}$ with a high growth restriction factor allows the rapid building up of an effective constitutional supercooling zone ahead of the growing crystal, resulting in a significant grain refinement. ${ }^{22}$ Consequently, the grain structure of all the as-cast alloys are relatively homogeneous and the grains are not very coarse after the addition of $\mathrm{Zr}$. It is found that the microstructures of $\mathrm{Ca}$-containing and Ca-free alloys are very different in both the as-cast and hot-extruded conditions. For the as-cast alloys, due to the high cooling rate associated with direct chill casting, the solidification process proceeds under a non-equilibrium condition. The distribution of Ca tends to be inhomogeneous after solidification. Since the solid solubility of $\mathrm{Ca}$ is low in $\mathrm{Mg}$ (max. 0.7 wt. $\%$ at $\left.516.5^{\circ} \mathrm{C}^{23}\right)$, most of the $\mathrm{Ca}$ atoms contribute to the formation of $\mathrm{Mg}_{2} \mathrm{Ca}$ phases at dendritic and grain boundaries.
For the hot-extruded alloys, T4 heat-treatment at $500^{\circ} \mathrm{C}$ and preheating treatment at $400^{\circ} \mathrm{C}$ were performed before the final extrusion. The $\mathrm{Mg}_{2} \mathrm{Ca}$ compounds in the as-cast alloys are expected to be fully dissolved into the matrix during T4 heattreatment, since the maximum solid solubility of $\mathrm{Ca}$ in $\mathrm{Mg}$ at $500^{\circ} \mathrm{C}$ is approximate $0.65 \mathrm{wt} . \%$, which is higher than the Ca content contained in the current experimental alloys. The solid solubility of $\mathrm{Ca}$ at $400^{\circ} \mathrm{C}$ decreases to lower than 0.3 wt.\%. As a result, $\mathrm{Ca}$ solutes tended to precipitate and grow as the $\mathrm{Mg}_{2} \mathrm{Ca}$ particles shown in the SEM BSE micrographs in Fig. 2e and $f$ during the preheating treatment. Furthermore, plastic deformation could generate a large amount of dislocations. The stress field around these dislocations could provide the driving force for mass transfer, ${ }^{24}$ and the dislocations can serve as nucleation points for precipitation. It should be noted that the formation of precipitates is related to the dislocation density. In the current work, the extrusion temperature is $400^{\circ} \mathrm{C}$, at which the internal stress could be released and the dislocations tended to be dynamically recovered. Thus, the dislocation density could be decreased significantly and the formation of precipitates could be restricted during hot-extrusion. As shown in Fig. 4, only a small number of fine $\mathrm{Mg}_{2} \mathrm{Ca}$ precipitates were found in the matrix.

Compared to the hot-extruded Ca-free alloys, Cacontaining alloys exhibit a finer grain microstructure. Similar results can also be found in the previous studies on Ca-containing alloys. ${ }^{15,25,26} \mathrm{It}$ was suggested that the grain refinement effect of $\mathrm{Ca}$ for extruded $\mathrm{Mg}$ alloys is most likely a consequence of the influence of $\mathrm{Ca}$ on the dynamic recrystallization. ${ }^{27}$ The precipitates formed during preheating and hot-extrusion play an important role in refining the grains of hot-extruded Ca-containing alloys. As shown in Figs. 2e, $\mathrm{f}$ and 4 , the $\mathrm{Mg}_{2} \mathrm{Ca}$ precipitates are distributed along grain boundaries and among the matrix, which could pin the grain boundary movement and prevent the grain growth during hotextrusion.

Regarding the creep behavior of the as-cast alloys, there exist two competitive effects on the creep properties with increasing $\mathrm{Ca}$ content. First, the decreased grain size caused by $\mathrm{Ca}$ addition would worsen the creep resistance. ${ }^{28}$ It is well known that, with increasing temperature, the grain boundaries become weak regions and creep deformations can easily occur by grain sliding. Finer grains mean a higher density of grain boundaries, in other words, a higher amount of weak regions. Therefore, creep could proceed more easily in the alloys with finer grains. Second, the thermally stable $\mathrm{Mg}_{2} \mathrm{Ca}$ particles formed along the dendritic and grain boundaries could effectively enhance the creep resistance by their pinning effects on the grain boundary sliding. In the as-cast alloys, the grain size did not change much with the addition of $\mathrm{Ca}$. Apparently, the strengthening of the $\mathrm{Mg}_{2} \mathrm{Ca}$ particles plays a 
more dominant role than the weakening of refined grains in influencing the creep deformation. As a result, the creep properties of the as-cast alloys are improved by $\mathrm{Ca}$ addition. As to the extruded alloys, apart from the influence of grain size on the creep properties, the homogeneously distributed $\mathrm{Mg}_{2} \mathrm{Ca}$ precipitates are expected to effectively enhance the creep resistance by blocking the dislocation motion as well as the grain boundary sliding. Due to the extremely reduced grain size caused by 0.6 wt. $\% \mathrm{Ca}$ addition (Fig. 1f), the weakening effect of a higher density of grain boundaries on the creep resistance plays a more important role than the strengthening effect of the $\mathrm{Mg}_{2} \mathrm{Ca}$ precipitates, even though the hot-extruded $\mathrm{Mg}-0.6 \mathrm{Ca}-0.5 \mathrm{Zr}$ has a relatively higher density of $\mathrm{Mg}_{2} \mathrm{Ca}$ precipitates. Thus, unlike the as-cast alloy with $0.6 \mathrm{wt} . \% \mathrm{Ca}$, the extruded alloy with 0.6 wt.\% Ca shows a lower creep resistance than that with 0.3 wt.\% Ca. As already mentioned, the addition of $0.3 \mathrm{wt} . \% \mathrm{Ca}$ shows an excellent strengthening effect on the creep resistance of alloys in both the as-cast and hot-extruded conditions. However, compared with the as-cast alloy, the addition of $0.3 \mathrm{wt} . \% \mathrm{Ca}$ to the extruded alloy results in a better improvement in creep resistance. The much greater enhancement of creep properties caused by $0.3 \mathrm{wt} . \% \mathrm{Ca}$ addition in the hot-extruded alloys may be attributed to the different morphology and distribution of second-phase particles in its microstructure compared to that in the as-cast alloys.

As shown in Fig. $6 \mathrm{c}$ and $\mathrm{d}$, the true stress exponent $n_{\mathrm{t}}$ values of the as-cast and extruded Mg-Ca-Zr alloys are around 3-5 between $40 \mathrm{MPa}$ and $80 \mathrm{MPa}$ at $200^{\circ} \mathrm{C}$, indicating that the viscous glide of dislocation and dislocation climbing are the dominant rate-controlling deformation mechanisms during the creep deformation at $200^{\circ} \mathrm{C}$. Based on this main creep mechanism, the more significantly improved creep properties for the extruded alloys could be explained as follows. In the as-cast alloys, although the coarse $\mathrm{Mg}_{2} \mathrm{Ca}$ compounds distributed along the grain boundaries could effectively block grain boundary sliding at elevated temperatures, their impeding effects on the dislocation motions are too limited. In contrast, in the extruded alloys, the homogeneously distributed $\mathrm{Mg}_{2} \mathrm{Ca}$ spherical particles as well as the precipitates lying in the matrix could not just pin the grain boundary sliding but also serve as effective obstacles to hinder the dislocation motions. As a result, the addition of $\mathrm{Ca}$ shows a more significant effect on enhancing the creep properties for the extruded alloys. It can be concluded that the effects of $\mathrm{Ca}$ on the creep properties of $\mathrm{Mg}-\mathrm{Ca}-\mathrm{Zr}$ alloys are strongly related to the morphology and distribution of second-phase particles. The finer and more homogeneously distributed $\mathrm{Mg}_{2} \mathrm{Ca}$ particles have a greater effect on improving the creep resistance than the coarser $\mathrm{Mg}_{2} \mathrm{Ca}$ particles distributed along the grain boundaries.

\section{CONCLUSION}

The effects of the morphology and distribution of second phases on the creep behavior of as-cast and hot-extruded $\mathrm{Mg}-\mathrm{Ca}-\mathrm{Zr}$ alloys were investigated. The following conclusions can be drawn:

- The as-cast microstructures of $\mathrm{Mg}-\mathrm{Ca}-\mathrm{Zr}$ alloys consist of $\alpha-\mathrm{Mg}$ and coarse $\mathrm{Mg}_{2} \mathrm{Ca}$ compounds distributed along dendritic and grain boundaries, while the hot-extruded microstructures are composed of $\mathrm{Mg}_{2} \mathrm{Ca}$ precipitates and spherical particles homogeneously distributed in the matrix and along grain boundaries.

- The creep resistance of both the as-cast and hotextruded $\mathrm{Mg}-\mathrm{Ca}-\mathrm{Zr}$ alloys can be improved by 0.3 wt.\% $\mathrm{Ca}$ addition. With further addition of Ca more than 0.3 wt.\%, the creep property of the extruded alloys is worsened due to the extremely reduced grain size.

- The effect of Ca on the creep properties of $\mathrm{Mg}$-Ca alloys is strongly related to the morphology and distribution of the $\mathrm{Mg}_{2} \mathrm{Ca}$ phases. The finer and more homogeneously distributed $\mathrm{Mg}_{2} \mathrm{Ca}$ particles have a greater effect on improving the creep properties.

\section{ACKNOWLEDGEMENTS}

The authors are grateful to Mr. G. Meister from MagIC at Helmholtz-Zentrum Geesthacht for technical support. One of the authors (S. You) acknowledges the financial support from the China Scholarship Council (CSC).

\section{REFERENCES}

1. K.U. Kainer, Magnesium Alloys and Technology, 1st ed. (Germany: Wiley, 2003), pp. 1-3.

2. A.A. Luo, J. Magnes. Alloys 1, 2 (2013).

3. B. Mordike, Mater. Sci. Eng. A. 324, 103 (2002).

4. N. Mo, Q. Tan, B. Jiang, F. Pan, and M.-X. Zhang, Metall. Mater. Trans. A 48, 5710 (2017).

5. J. TerBush, A. Suzuki, N. Saddock, J. Jones, and T. Pollock, Scr. Mater. 58, 914 (2008).

6. S. Xu, N. Matsumoto, K. Yamamoto, S. Kamado, T. Honma, and Y. Kojima, Mater. Sci. Eng. A 509, 105 (2009).

7. B. Kondori and R. Mahmudi, Mater. Sci. Eng. A 700, 438 (2017).

8. M. Yang, L. Cheng, J. Shen, and F. Pan, Rare Met. 28, 576 (2009).

9. D.H. StJohn, M. Qian, M.A. Easton, P. Cao, and Z. Hildebrand, Metall. Mater. Trans. A 36, 1669 (2005).

10. J. Fan, G. Yang, Y. Zhou, Y. Wei, and B. Xu, Metall. Mater. Trans. A 40, 2184 (2009).

11. N. Zhou, Z.Y. Zhang, J. Dong, L. Jin, and W.J. Ding, Mater. Sci. Eng. A 560, 103 (2013).

12. K. Ozturk, Y. Zhong, A.A. Luo, and Z.K. Liu, Jom-J Min. Met. Mat. S 55, A40 (2003).

13. Y. Terada, D. Itoh, and T. Sato, Mater. Sci. Eng. A 523, 214 (2009).

14. F.R. Elsayed, N. Hort, M.A. Salgado Ordorica, and K.U. Kainer, Mater. Sci. Forum 690, 65 (2011).

15. J.C. Oh, T. Ohkubo, T. Mukai, and K. Hono, Scr. Mater. 53, 675 (2005).

16. K. Oh-ishi, R. Watanabe, C.L. Mendis, and K. Hono, Mater. Sci. Eng. A 526, 177 (2009).

17. H. Pan, G. Qin, Y. Ren, L. Wang, S. Sun, and X. Meng, J. Alloys Compd. 630, 272 (2015). 
18. K.R. Athul, U.T.S. Pillai, A. Srinivasan, and B.C. Pai, $A d v$. Eng. Mater. 18, 770 (2016).

19. H. Somekawa, K. Hirai, H. Watanabe, Y. Takigawa, and K. Higashi, Mater. Sci. Eng. A 407, 53 (2005).

20. Y. Li and T.G. Langdon, Scr. Mater. 36, 1457 (1997).

21. J. Gibeling and W. Nix, Mater. Sci. Eng. 45, 123 (1980).

22. D.H. StJohn, M.A. Easton, M. Qian, and J.A. Taylor, Metall. Mater. Trans. A 44, 2935 (2013).

23. M. Aljarrah and M. Medraj, CALPHAD 32, 240 (2008).

24. D. Blavette, E. Cadel, A. Fraczkiewicz, and A. Menand, Science 286, 2317 (1999).
25. Y. Ortega, M.A. Monge, and R. Pareja, J. Alloys Compd. 463, $62(2008)$.

26. L. Geng, B. Zhang, A. Li, and C. Dong, Mater. Lett. 63, 557 (2009).

27. B. Zhang, Y. Wang, L. Geng, and C. Lu, Mater. Sci. Eng. A 539, 56 (2012).

28. R. Coble, J. Appl. Phys. 34, 1679 (1963).

Publisher's Note Springer Nature remains neutral with regard to jurisdictional claims in published maps and institutional affiliations. 